\title{
Effect of Acute and Daily Neurotensin and Enkephalin Treatments on Extracellular Dopamine in the Nucleus Accumbens
}

\author{
Peter W. Kalivas and Patricia Duffy \\ Department of Veterinary and Comparative Anatomy, Pharmacology and Physiology, Washington State University, \\ Pullman, Washington 99164-6520
}

\begin{abstract}
The injection of neurotensin or the enkephalin analog TyrD-Ala-Gly-MePhe-Gly(ol) (DAMGO) into the $A 10$ region of rats produces a motor stimulant effect that is associated with an increase in the postmortem levels of dopamine metabolites in the nucleus accumbens. These behavioral and neurochemical effects are augmented following daily administration. In vivo dialysis in the nucleus accumbens of conscious rats was used to determine if the acute and augmented behavioral responses following neurotensin or DAMGO administration are associated with an increase in extracellular dopamine concentrations. The acute injection of DAMGO produced a dose-dependent (0.03-3.3 nmol) elevation in extracellular dopamine and its metabolites in the nucleus accumbens. Neurotensin also produced a dose-related (0.1-3.3 $\mathrm{nmol}$ ) increase in dopamine and its metabolites. The elevation in extracellular dopamine produced by DAMGO, but not by neurotensin, was positively correlated with the increase in motor activity. Following daily treatment of either neurotensin $(1.0 \mathrm{nmol} \times 4 \mathrm{~d})$ or DAMGO $(0.03 \mathrm{nmol}$ $\times 4 \mathrm{~d}$ ), a significant elevation in extracellular dopamine levels occurred in the nucleus accumbens compared to an acute injection. The time course of the change in extracellular dopamine after daily injections was similar to the time course of the behavioral stimulation for both compounds. These data demonstrate that enhanced dopamine release in the nucleus accumbens mediates the acute behavioral effect of DAMGO but does not entirely explain the motor effects of neurotensin. However, enhanced dopamine release may mediate the behavioral sensitization produced by daily injection of both peptides into the $\mathbf{A} 10$ region.
\end{abstract}

Neurotensin and Met-enkephalin are neuropeptides that modulate the activity of dopamine neurons in the ventromedial mesencephalon. Neurotensin receptors are located directly on dopaminergic perikarya (Palacios and Kuhar, 1981; Quirion et al., 1985; Dilts and Kalivas, 1989; Dana et al., 1989), and activation of these receptors by neurotensin produces an increase in impulse generation, both directly and indirectly by inhibiting autoreceptor-induced hyperpolarization (Innis et al., 1985; Pin-

Received Dec. 7, 1989; revised Mar. 12, 1990; accepted Apr. 9, 1990.

This work was supported in part by USPHS Grants MH-40817, DA-03906, and NS-24388. We wish to thank Jenny Baylon for assistance in preparing the manuscript.

Correspondence should be addressed to Peter Kalivas, Ph.D., at the above address.

Copyright (c) 1990 Society for Neuroscience $0270-6474 / 90 / 092940-10 \$ 03.00 / 0$ nock, 1985; Shi and Bunney, 1988; Seutin et al., 1989). Supporting an excitatory modulation of dopamine cells by neurotensin, microinjection of neurotensin into the Al0 dopamine region elicits a motor stimulant response that is blocked by pretreatment with dopamine antagonists (Kalivas et al., 1983a; Cador et al., 1985) and increases measures of dopamine turnover in limbic dopamine axonal terminal fields (Kalivas et al., 1983a; Phillips et al., 1988; Cador et al., 1989).

Enkephalin acts on the $\mu$-opioid receptor subtype (Latimer et al., 1987) to indirectly activate dopamine neurons. Thus, unlike neurotensin receptors, $\mu$-opioid receptors are located on nondopaminergic neurons in the ventromedial mesencephalon (Dilts and Kalivas, 1989). While activation of $\mu$-receptors inhibits the activity of the nondopaminergic neurons, it indirectly stimulates the dopamine perikarya (Gysling and Wang, 1983; Matthews and German, 1984; Lacey et al., 1989). Injection of enkephalin analogs into the $\mathrm{A} 10$ region increases locomotor activity by a dopamine-dependent mechanism (Broekkamp et al., 1979; Kelley et al., 1980; Joyce et al., 1981; Kalivas et al., 1983b). IntraA 10 injection of enkephalin analogs also increases the levels of dopamine metabolites in A 10 dopamine terminal fields (Kalivas et al., 1983b; Latimer et al., 1987; Cador et al., 1989). Based upon these findings, it has been postulated that enkephalin may stimulate dopamine cells via disinhibition of GABAergic afferents (Kelley et al., 1980; Kalivas et al., 1990), and it was recently shown that pretreatment with the $\mathrm{GABA}_{\mathrm{B}}$ agonist baclofen abolished the capacity of intra-A10 injection of enkephalin analog to increase motor activity and dopamine metabolites in the nucleus accumbens (Kalivas et al., 1990).

When either neurotensin or $\mu$-opioids are microinjected daily into the A10 dopamine region, the acute motor stimulant effect of these compounds is augmented (Joyce and Iversen, 1979; Vezina and Stewart, 1984; Kalivas, 1985; Kalivas and Taylor, 1985; Elliot and Nemeroff, 1986). Furthermore, the increase in postmortem levels of dopamine metabolites in the nucleus accumbens by microinjected neurotensin or enkephalin analog is augmented following daily administration (Kalivas, 1985; Kalivas and Taylor, 1985). The augmented behavioral response appears to be analogous to the behavioral sensitization produced by daily administration of the indirect dopamine agonists amphetamine and cocaine (Robinson and Becker, 1986; Kuzcenski and Segal, 1988; Post and Weiss, 1988). Recently it has been demonstrated using in vivo dialysis in the nucleus accumbens or striatum of the conscious rat that the behavioral sensitization produced by daily amphetamine or cocaine administration is associated with an augmentation in the extracellular concentrations of dopamine (Robinson et al., 1988; Kazahaya et al., Kalivas and Duffy, 1990). 
In the present study, in vivo dialysis in the nucleus accumbens of the conscious rat was used to determine if the behavioral stimulation following acute administration of neurotensin or the $\mu$-opioid enkephalin analog Tyr-D-Ala-Gly-MePhe-Gly(ol) (DAMGO) into the A10 region is associated with an increase in extracellular dopamine levels. Furthermore, the peptides were administered daily to investigate whether the augmented motor stimulant response was associated with an augmented elevation in extracellular dopamine concentration.

\section{Materials and Methods}

Animal housing, surgery, drugs, and microinjection procedure. Male Sprague-Dawley rats (Laboratory Animal Research Facility, Pullman, WA) were individually housed in a temperature- and humidity-controlled environment with food and water made available ad libitum. Rats weighing 250-350 gm were anesthetized with Equithesin, i.p., mounted in a stereotaxic apparatus, and were implanted with a unilateral cannula (20 gauge stainless steel; Small Parts, Miami, FL) $3 \mathrm{~mm}$ over the nucleus accumbens $(\mathrm{A} / \mathrm{P} 9.1 \mathrm{~mm} ; \mathrm{M} / \mathrm{L} 1.7 \mathrm{~mm}$; D/V $0.0 \mathrm{~mm}$; relative to the interaural line; Pellegrino et al., 1979) for later insertion of a dialysis probe. A stainless steel obturator (25 gauge; Small Parts) was inserted into the chronic cannula. In addition, the rats were implanted with bilatcral stainless steel guide cannulae (26 gauge; Small Parts) $1 \mathrm{~mm}$ dorsal to the A10 dopamine region (A/P $2.6 \mathrm{~mm} ; \mathrm{M} / \mathrm{L}$ $0.6 \mathrm{~mm} ; \mathrm{D} / \mathrm{V}-2.5 \mathrm{~mm})$. The cannulae were angled $\left(6^{\circ}\right)$ to avoid penetration of the midsagittal sinus or cerebral aqueduct. Obturators (33 gauge stainless steel; Small Parts) were placed in the guide cannulae, and the rats were allowed a minimum $7 \mathrm{~d}$ recovery period prior to behavioral testing.

Microinjection of sterile, isotonic saline vehicle ( $0.5 \mu \mathrm{l} /$ side), neurotensin (Bachem, Inc., Torrance, CA) or DAMGO (Bachem) were made into the A 10 region over $60 \mathrm{sec}$ by inserting an injection needle (33 gauge stainless steel tubing; Small Parts) $1 \mathrm{~mm}$ below the end of the chronic guide cannula. Simultaneous bilateral infusions were made into the unrestrained rat using $1 \mu \mathrm{l}$ syringes (Hamilton, Reno, NV) mounted in an infusion pump (Sage, USA) that was connected to the injection needle via PE-10 tubing. Twenty scconds after completing the infusion, the injection needles were removed and the obturators replaced.

Behavioral measurements. Rat motor behavior was monitored in 4 photocell chambers (Omnitech, Columbus, $\mathrm{OH}$ ) located inside individual wooden boxes with separate air supply and light source (see Latimer et al. 1987, for details). At least $24 \mathrm{hr}$ prior to beginning behavioral studies, the rats were placed in the photocell cage for $60 \mathrm{~min}$, and patency of the dialysis cannula was verified, and a sham injection was made that consisted of inserting a 33 gauge needle into the A10 region. On the day of a behavioral trial or the night prior to the trial, the rats were placed into a photocell cage and a dialysis probe was inserted into the nucleus accumbens. Following a minimum $120 \mathrm{~min}$ or overnight equilibration period, baseline samples of dialysate $(20 \mathrm{~min}$ each) were collected for 60 or $80 \mathrm{~min}$. The rats then received an intra-A10 microinjection of saline, ncurotensin, or DAMGO, and samples of dialysate were obtained every $20 \mathrm{~min}$ for 120 or $180 \mathrm{~min}$. Following the experiment, the dialysis probe was removed, the obturator replaced, and the rat returned to its home cage. For the dose-response study, each rat was tested a maximum of 3 times with a different dose of neurotensin or DAMGO separated by a minimum $72 \mathrm{hr}$ intertrial interval. Previous studies demonstrate that separation of acute DAMGO or neurotensin microinjections by $72 \mathrm{hr}$ prevents the development of behavioral sensitization observed after daily injections (Kalivas and Taylor, 1985; Kalivas, 1985; Elliot and Nemeroff, 1986). For the sensitization study, following the first injection in the dialysis chamber with saline, neurotensin $(1.0 \mathrm{nmol})$ or DAMGO $(0.03 \mathrm{nmol})$, the rats received a daily injection of the same treatment for the next $3 \mathrm{~d}$ in the home cage. The doses of peptide used in the daily treatment study were based upon published or preliminary data demonstrating bchavioral sensitization after daily administration (Kalivas and Taylor, 1985; Elliot and Nemeroff, 1986). Three to six days later, the rats were returned to the photocell cage, and dialysis and drug injections performed as described above for the first day of the experiment.

Dialysis and neurochemical measurements. The dialysis probe was constructed as described by Robinson and Whishaw (1988). Two to 3 $\mathrm{mm}$ of dialysis tubing was exposed at the tip of the probe. The probe was inserted into a connector that allowed control of the depth of penetration and fixation onto the chronically implanted guide cannula. The connector was attached to a liquid swivel, which was located on a balance beam to minimize discomfort to the rat. In 56 of the 95 experiments, either prior to inserting the probe or after removing the probe from the rat, recovery was determined by placing the probe for $20 \mathrm{~min}$ in the dialysate buffer $\left(5 \mathrm{~mm} \mathrm{KCl}, 120 \mathrm{~mm} \mathrm{NaCl}, 1.8 \mathrm{~mm} \mathrm{CaCl}_{2}, 1.2\right.$ $\mathrm{mM} \mathrm{MgCl}_{2}$ plus $0.2 \mathrm{mM}$ PBS to give $\left.\mathrm{pH} 7.4\right)$ containing dopamine $\left(10^{-7}\right.$ M), 3,4-dihydroxyphenylacetic acid (DOPAC; $10^{-6} \mathrm{M}$ ), homovanillic acid (HVA; $10^{-6} \mathrm{M}$ ), and 5-hydroxyindoleacetic acid (5-HIAA; $10^{-6} \mathrm{M}$ ). The mean \pm SEM percent recoveries at room temperature were as follows: dopamine, $9.3 \pm 0.6$; DOPAC, $20.4 \pm 1.4$; HVA, $13.0 \pm 1.2$; and 5-HIAA, $8.1 \pm 0.4$. The flow rate was $2.13 \mu \mathrm{l} / \mathrm{min}$ (Harvard Instruments) throughout the experiment, and the concentrations of dopamine, DOPAC, HVA, and 5-HIAA were determined using HPLCEC. The dialysis samples were collected into $20 \mu \mathrm{l}$ of mobile phase [0.1 M citric acid, $75 \mathrm{mM} \mathrm{Na} \mathrm{HPO}_{4}, 0.6-1.0 \mathrm{~mm}$ heptane sulfonic acid, 0.1 mM EDTA, $13 \%$ methanol (vol/vol), pH 3.8 -4.2 , with 2.0 pmol dihydroxybenzylamine as the internal standard], and the entire sample was injected into the HPLC system. A reversed-phase column $(C-18,25 \mathrm{~cm}$; Bioanalytical, Indianapolis, IN) was used to separate the biogenic amines, and a coulometric electrochemical detection system (ESA, Inc., Bedford, MA) utilizing 3 electrodes (preinjection port guard electrode $=+0.4$ $\mathrm{V}$, prenxidation electrode $=+0.02 \mathrm{~V}$, working electrode $=+0.35 \mathrm{~V}$ ) was used to oxidize the amines. Standard curves ranging from 0.01 to $10 \mathrm{pmol}$ were used to quantify each compound.

Histology and statistics. Rats were killed with an overdose of pentobarbital, and their brains were perfused via intracardiac infusion with PBS $(60 \mathrm{ml})$ followed by $10 \%$ paraformaldehyde-saline $(60 \mathrm{ml})$. The brains were stored in 10\% formaldehyde for at least a week. Coronal sections $(100 \mu \mathrm{m}$ thick) were made of the cannulae tracks with a vibratome, mounted on gelatin-coated slides, and stained with cresyl violet. The location of the dialysis probe track or tip of the microinjection cannulae was determined by an individual unaware of the animal's behavioral or neurochemical response. The time-course behavioral and neurochemical data were statistically evaluated using a 2-way repeatedmeasures analysis of variance (ANOVA), followed by the least-significant difference test for multiple comparisons, as described by Milliken and Johnson (1984). The cumulative behavioral and neurochemical data were analyzed using a 1-way ANOVA, followed by a Dunnett's test for comparison to saline. Prior to data analysis and presentation, the neurochemical data were converted to percent change from the average of the 3 baseline measurements. Table 1 shows the concentration of each amine not corrected for probe recovery. Correlation coefficients for comparing amine levels to locomotor behavior were obtained using linear-regression analysis.

\section{Results}

\section{Effect of acute DAMGO and neurotensin on extracellular dopamine}

Figure $1 A$ shows that DAMGO injection into the $\mathrm{A} 10$ region produced a dose-dependent increase in horizontal photocell counts. A dose of 0.03 mmol elicited a significant elevation during the first $20 \mathrm{~min}$ after injection, and the largest dose (3.3 nmol) produced a maximal response between 80 and $120 \mathrm{~min}$ after injection. A latency to maximal response following injection of relatively large doses of $\mu$-opioid agonists into the A10 region is consistent with previous reports (Joyce et al., 1981; Kalivas et al., 1983b). Figure $1 B$ shows that DAMGO produced a dose-dependent elevation in the extracellular concentration of dopamine in the nucleus accumbens. The increase was statistically significant after the 2 largest doses of DAMGO $(0.3$ and $3.3 \mathrm{nmol}$ ) between 40 and $100 \mathrm{~min}$ after injection. Figure 2 shows that DAMGO also elevated the levels of the dopamine metabolites, DOPAC and HVA, and the serotonin metabolite, 5-HIAA, in the extracellular fluid in the nucleus accumbens. The increase in DOPAC was dose-dependent, and significant elevations began at $40 \mathrm{~min}$ after the injection of all doses. All doses of DAMGO significantly elevated the level of HVA by $40 \mathrm{~min}$ after injection, and the levels remained enhanced for 
Table 1. Raw baseline values for the biogenic amines recovered from the dialysis probe

\begin{tabular}{lcccccc} 
& \multicolumn{2}{l}{ Dose-response study } & & Sensitization study & \\
\cline { 2 - 3 } \cline { 5 - 6 } Compound & $\begin{array}{l}\text { Neurotensin } \\
(34)\end{array}$ & DAMGO (26) & & Saline (9) & DAMGO (14) & $\begin{array}{l}\text { Neurotensin } \\
(12)\end{array}$ \\
\hline Dopamine & $6.9 \pm 1.0$ & $6.8 \pm 1.1$ & & $3.4 \pm 0.8$ & $5.6 \pm 1.1$ & $3.3 \pm 1.4$ \\
DOPAC & $444.9 \pm 83.7$ & $321.0 \pm 64.2$ & & $349.8 \pm 137.2$ & $467.4 \pm 35.2$ & $387.5 \pm 59.5$ \\
HVA & $227.9 \pm 42.8$ & $196.8 \pm 46.2$ & & $172.4 \pm 29.2$ & $177.5 \pm 30.9$ & $294.0 \pm 82.3$ \\
5-HIAA & $66.3 \pm 13.2$ & $68.1 \pm 14.1$ & & - & - & -
\end{tabular}

Data shown are mean $+\mathrm{SEM} \mathrm{fmol} / \mathrm{min}$ of the average of the 3 baseline samples collected prior to microinjection of peptide or saline. The data are not corrected for probe recovery. The number in parentheses refers to the number of rats used in each experiment.

the duration of the experiment. The 2 largest doses of DAMGO were found to increase the concentration of 5-HIAA from 40 min to the end of the expcriment, and at the lowest dose statistical significance was observed at 40 and 120 min after injection. Figures 1 and 2 also show the cumulative behavioral and neurochemical responses for $120 \mathrm{~min}$ following DAMGO microinjection. All doses of DAMGO significantly elevated photocell counts, DOPAC, HVA, and 5-HIAA, while only the 2 largest doses increased extracellular dopamine levels.

Figure 3 shows that neurotensin significantly increased horizontal photocell counts and the extracellular level of dopamine in the nucleus accumbens. The highest dose of neurotensin (3.3 nmol) significantly increased dopamine between 40 and $120 \mathrm{~min}$ after injection, while the next highest dose $(1.0 \mathrm{nmol})$ elevated dopamine between 60 and $120 \mathrm{~min}$. Behavioral activity was elevated by the 3 highest doses of neurotensin. However, the time course of the behavioral response was different depending upon the dose. At the 2 highest doses (1.0 and $3.3 \mathrm{nmol})$, the majority of the hyperactivity occurred beyond $40 \mathrm{~min}$ after injection, while at a lower dose $(0.3 \mathrm{nmol})$, the increase occurred at 20 min after injection. Figure 4 demonstrates that all doses of neurotensin significantly elevated DOPAC by $60 \mathrm{~min}$ after injection, with the 3 highest doses producing an effect by 40 min after injection. HVA was also increased after all doses of neurotensin by $60 \mathrm{~min}$ after injection. The effect of neurotensin on extracellular 5-HIAA was not dose-dependent. The most marked effects were produced by the lowest and highest doses. Figures 3 and 4 also show the cumulative behavioral and neurochemical responses. By this measure, all doses of neurotensin employed significantly elevated DOPAC and HVA. The 2 highest doses of neurotensin increased dopamine, while the lowest and highest doses elevated 5-HIAA. Only the largest dose of neurotensin significantly elevated horizontal photocell counts.

\section{Effect of daily DAMGO and neurotensin injection into the A10 region}

DAMGO $(0.03 \mathrm{nmol})$, neurotensin $(1.0 \mathrm{nmol})$, or saline was administered into the $\mathrm{A} 10$ region once a day for $4 \mathrm{~d}$. Figure 5 shows that after daily neurotensin administration, an acute injection of neurotensin given 4-6 d later produced a significant elevation in both photocell counts and extracellular dopamine levels in the nucleus accumbens compared to the first day of administration. The time course for both effects was similar, with a peak effect after daily administration occurring at $40 \mathrm{~min}$ after injection. The increases in DOPAC or HVA were not significantly augmented over that produced by a single acute injection of neurotensin (Fig. 6). Figure 5 also demonstrates that the effect of DAMGO on both horizontal photocell counts and extracellular dopamine was augmented in rats pretreated with daily DAMGO. The time course of the increase in dopamine after DAMGO injection was similar to the motor response in that levels were elevated $20 \mathrm{~min}$ after injection and remained elevated for $120 \mathrm{~min}$. However, motor activity showed a maximum at $20 \mathrm{~min}$ after injection that was not reflected in extracellular dopamine. No augmentation was observed in the increase in DOPAC or HVA produced by an acute injection of DAMGO in daily DAMGO pretreated rats (Fig. 6). Figures 5 and 6 also show that daily administration of saline did not alter the effect of a subsequent acute injection of saline on horizontal photocell counts, dopamine, DOPAC, or HVA.

\section{Correlations between behavior and dopamine}

From the data in Figures 1-6 it appears that either dopamine and/or its metabolites could be significantly correlated with the behavioral response following the acute or daily injection of DAMGO or ncurotensin into the A10 region. When the cumulative changes in photocell counts were compared to the cumulative changes in dopamine, a significant correlation was observed after acute and daily injection of DAMGO, and after daily administration of neurotensin (Fig. 7). In contrast, dopamine and behavior were not correlated after acute administration of neurotensin. Behavior was not found to be significantly correlated with DOPAC, HVA, or 5-HIAA in any treatment group (Table 2). The concentration of dopamine was not correlated with any of its metabolites, except after daily neurotensin, for which case dopamine was positively correlated with the level of DOPAC. In all treatment groups, the level of DOPAC was positively correlated with the level of HVA.

\section{Histology}

Figure 8 illustrates the location of the dialysis probe in the nucleus accumbens and of the injection cannulae in the A10 dopamine region. Of the 55 rats used in this study, 47 were found to have both injection cannulae in the $A 10$ region (including the nucleus fascicularis, nucleus linearis, nucleus paranigralis, and nucleus parabrachialis pigmentosus), and all but 2 rats had at least $50 \%$ of the dialysis probe in the nucleus accumbens. The remaining portion of the probe was located dorsally in the mesolimbic striatum or ventrally in the olfactory tubercle.

\section{Discussion}

These data demonstrate that the motor stimulant response resulting from injection of the $\mu$-opioid agonist DAMGO, but not 

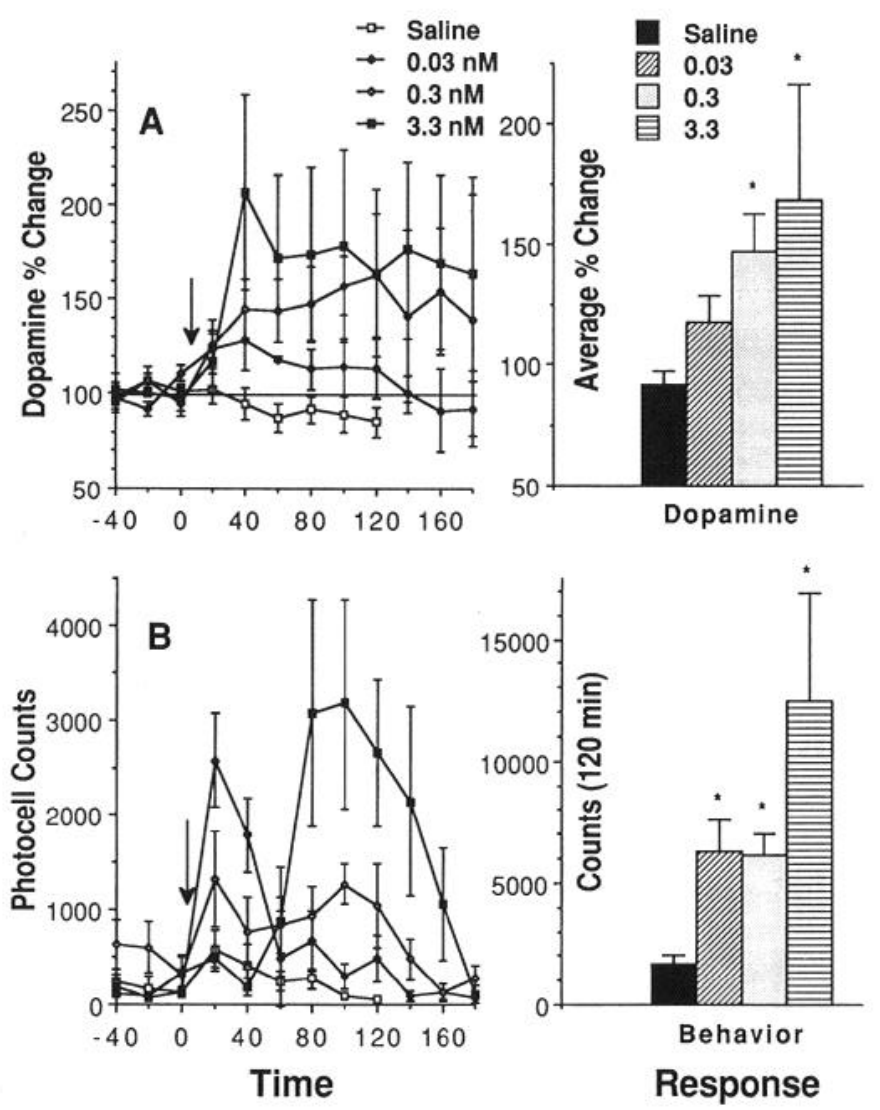

Figure 1. Effect of acute DAMGO injection into the A10 region on motor activity and extracellular dopamine in the nucleus accumbens. $A$. Dopamine in the nucleus accumbens is shown as percent \pm SEM change from the average of the 3 dialysis samples obtained prior to injection of saline or DAMGO. Dialysis samples were collected for 120 min following saline injection and for $180 \mathrm{~min}$ following DAMGO. Thus, statistical analysis was performed only out to $120 \mathrm{~min}$ after injection. The baseline values in this experiment are shown in Table 1. At right, the data are shown as the means \pm SEM average percent change over the $120 \mathrm{~min}$ after injection. This value was calculated by dividing the average of the values obtained after microinjection by the average of the baseline values obtained prior to injection. $B$, Horizontal photocell counts are shown as means \pm SEM. At right, the data are shown as the mean \pm SEM cumulative photocell counts over 120 min after injection. The arrow indicates the time of injection after the last baseline sample was collected at time $=0$. Saline, $N=9 ; 0.03 \mathrm{nmol}, N=8 ; 0.3$ $\mathrm{nmol}, N=5 ; 3.3 \mathrm{nmol}, N=4$. The time course data were statistically evaluated with a 2-way repeated measures ANOVA followed by a leastsignificant difference test for comparison of DAMGO to saline at a given time interval. $p<0.05$ for dopamine, 0.3 and $3.3 \mathrm{nmol}$ between 40 and $120 \mathrm{~min}$ treatment $F(3,22)=4.794, p=0.010$; time $F(8,176)=$ $3.651, p=0.001$; interaction $F(24,176)=3.156, p<0.001 . p<0.05$ for photocell counts, $0.03 \mathrm{nmol}$ at $20 \mathrm{~min}, 0.3 \mathrm{nmol}$ at 100 and 120 min, $3.3 \mathrm{nmol}$ at $80-120 \mathrm{~min}$, treatment $F(3,22)=8.607, p=0.001$; time $F(8,176)=10.524, p<0.001$; interaction $F(24,176)=5.839, p$ $<0.001 .{ }^{*} p<0.05$ for the cumulative data compared to saline injection using a 1-way repeated-measures ANOVA, followed by a Dunnett's test for multiple comparisons. For dopamine, $F(3,25)=4.800, p=0.010$, and for behavior, $F(3,25)=9.075, p=0.004$.

neurotensin, into the A10 region is positively correlated with an increase in extracellular dopamine content in the nucleus accumbens. Furthermore, when the behavioral stimulation response to these peptides was augmented by daily administration, the concentration of extracellular dopamine was found to increase in parallel.

The increase in extracellular dopamine in the nucleus accum-
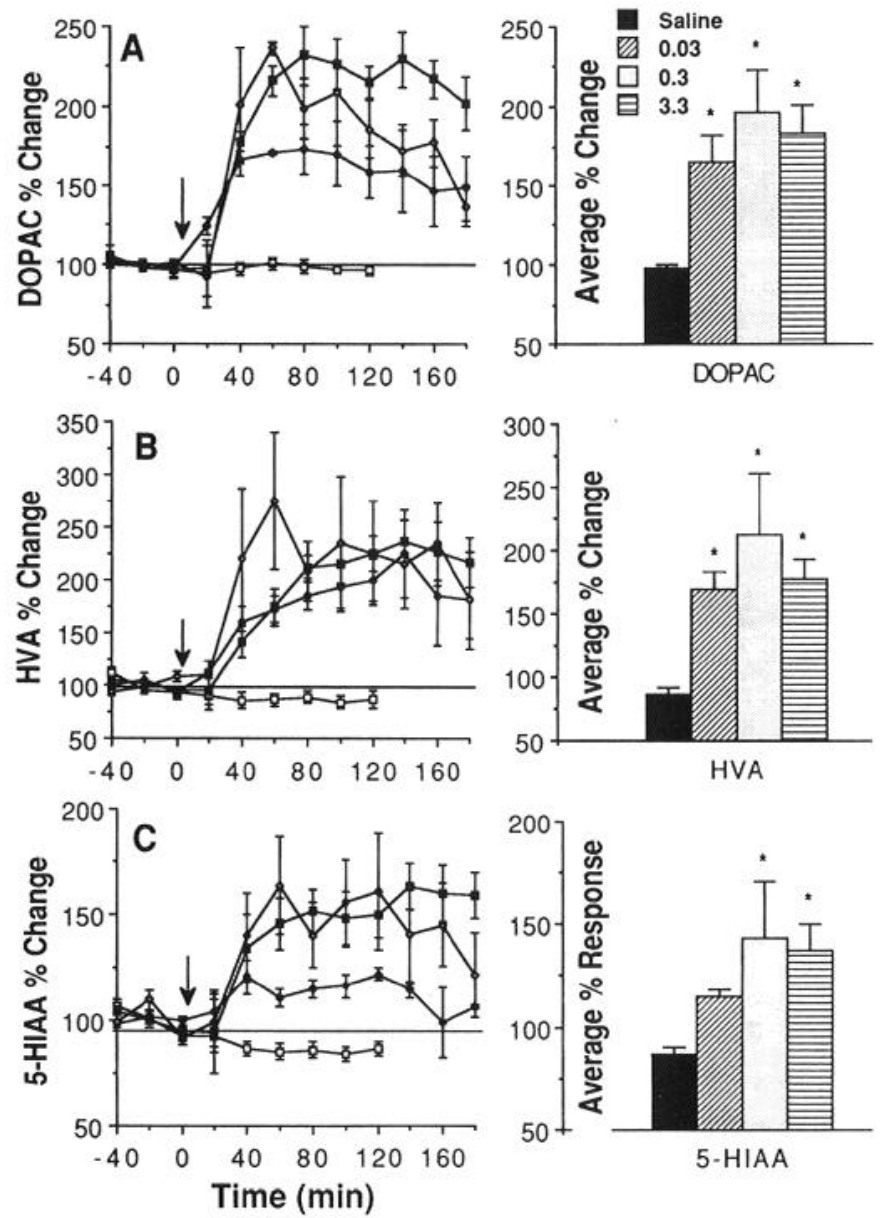

Figure 2. Effect of acute injection of DAMGO into the $\mathrm{A} 10$ region on extracellular levels of DOPAC, HVA, and 5-HIAA in the nucleus accumbens. The data were obtained simultaneously with the dopamine levels and behavior shown in Figure 1. $A$, DOPAC; $B$, HVA; $C$, 5-HIAA. Symbols: $\square$, saline; $0.03 \mathrm{nmol} ; \diamond, 0.3 \mathrm{nmol} ;, 3.3 \mathrm{nmol}$. See legend to Figure 1 for further details. For the time course data, a least-significant difference test was used. For DOPAC, $p<0.05$ difference from saline was observed at all doses from $40-120$ min; treatment $F(3,22)=17.552$, $p<0.001$; time $F(8,176)=30.094, p<0.001$; interaction $F(24,176)$ $=8.360, p<0.001$; for HVA, $p<0.05$ difference from saline was observed at all doses from $40-120 \mathrm{~min}$; treatment $F(3,22)=7.935, p$ $=0.001 ;$ time $F(8,176)=15.086, p<0.001$; interaction $F(24,176)=$ 5.606, $p<0.001$; for 5-HIAA, $p<0.05$ difference from saline was observed at 0.3 and $3.3 \mathrm{nmol}$ from 40 to $120 \mathrm{~min}$, at $0.03 \mathrm{nmol}$ at 40 and $120 \mathrm{~min}$; treatment $F(3,22)=7.780, p<0.001$; time $F(8,176)=$ $4.748, p<0.001$; interaction $F(24,176)=4.293, p<0.001 .{ }^{*} p<0.05$ for the cumulative data compared to saline injection using a 1-way ANOVA followed by a Dunnett's test. For DOPAC, $F(4,33)=6.492$, $p=0.001$; for HVA, $F(4,33)=7.623, p<0.001$; for 5 -HIAA, $F(4,33)=5.610, p=0.002$.

bens by acute injection of DAMGO is consistent with previous studies showing that the motor stimulant response produced by $\mu$-opioid agonist administration into the A10 region is blocked by intra-accumbens administration of dopamine antagonist or depletion of dopamine in the nucleus accumbens by pretreatment with 6-hydroxydopamine (Kelley et al., 1980; Kalivas et al., 1983b). Also, the administration of $\mu$-opioids into the A10 region produces a dose-dependent elevation in the concentration of dopamine metabolites in postmortem nucleus accumbens tissue (Kalivas et al., 1983b; Latimer et al., 1987; Cador et al., 1989). Likewise, the fact that neurotensin elicited a dose-de- 

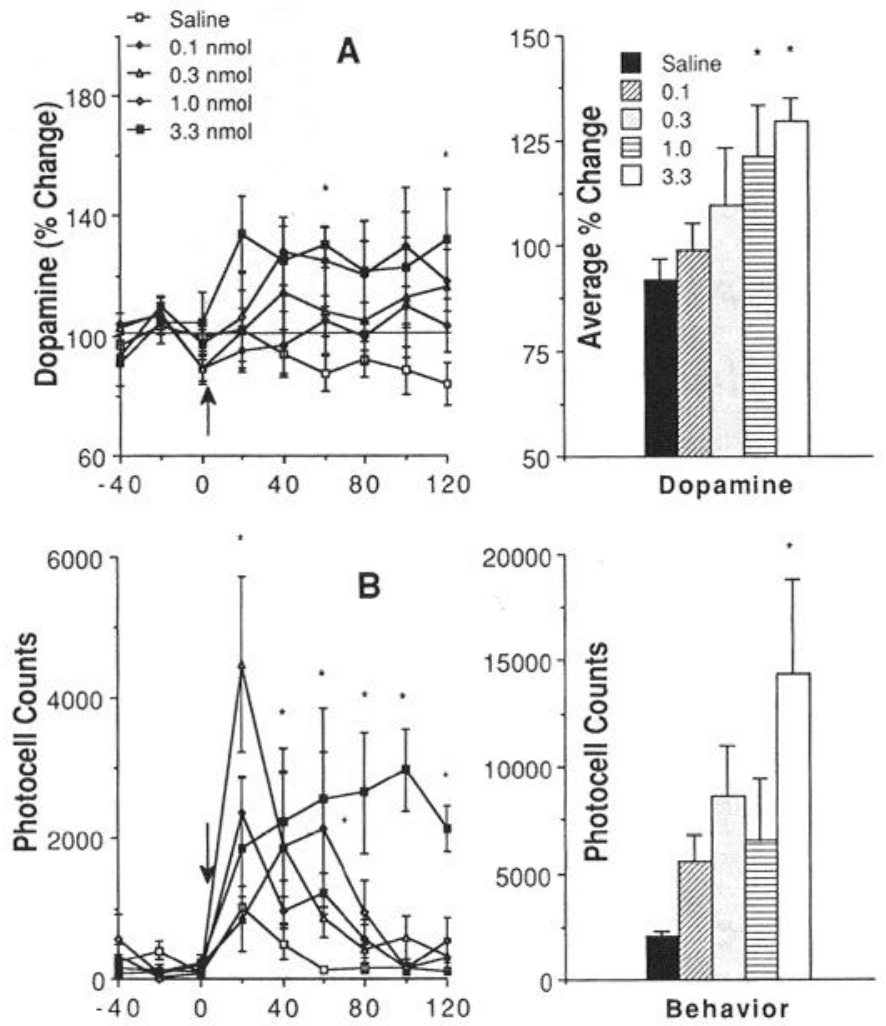

\section{Time ( $\mathrm{min})$}

Figure 3. Effect of acute injection of neurotensin into the Al0 region on motor activity and extracellular levels of dopamine in the nucleus accumbens. $A$, Dopamine in the nucleus accumbens is shown as percent change \pm SEM from the average of the 3 dialysis samples obtained prior to injection of saline or neurotensin. The baseline values in this experiment are shown in Table 1. At right, the data are shown as the mean \pm SEM average percent change over the 120 min after injection. This value was calculated by dividing the average of the values obtained after microinjection by the average of the baseline values obtained prior to injection. $B$, Horizontal photocell counts are shown as means $\pm \mathrm{SEM}$. At right, the data are shown as the mean \pm SEM cumulative photocell counts over $120 \mathrm{~min}$ after injection. The arrow indicates the time of injection after the last baseline sample collected at time $=0$. Saline, $N$ $=12 ; 0.1 \mathrm{nmol}, N=6 ; 0.3 \mathrm{nmol}, N=5 ; 1.0 \mathrm{nmol}, N=5 ; 3.3 \mathrm{nmol}$, $N=6$. The time-course data were statistically evaluated using a 2 -way repeated-measures analysis of variance followed by a least-significant difference multiple comparisons test for comparing neurotensin to saline treatment within a given time interval. $p<0.05$ for dopamine, $0.3 \mathrm{nmol}$ at $120 \mathrm{~min}, 1.0 \mathrm{nmol}$ at $40-120 \mathrm{~min}, 3.3 \mathrm{nmol}$ at $20,60,100$ and 120 min, treatment $F(4,29)=4.557, p=0.006$; time $F(8,232)=1.639, p$ $=0.115$; interaction $F(32,232)=1.894, p=0.004 . p<0.05$ for photocell counts, $0.3 \mathrm{nmol}$ at $20,1.0 \mathrm{nmol}$ at $60 \mathrm{~min}, 3.3 \mathrm{nmol}$ at $40-120$ min, treatment $F(4,29)=4.661, p=0.005$; time $F(8,232)=12.855$, $p<0.001$; interaction $F(32,232)=3.952, p<0.001{ }^{*} p<0.05$ for cumulative data compared to saline injection at each time point using a 1-way repeated-measures ANOVA, followed by a Dunnett's test for multiple comparisons. For dopamine, $F(4,33)=4.366, p=0.007$, and for behavior, $F(4,33)=4.914, p=0.004$.

pendent increase in extracellular dopamine in the nucleus accumbens corroborates a number of previous investigations indicating that neurotensin activates A10 dopamine neurons. IntraA10 injection of neurotensin increases motor activity (Kalivas et al., 1983b; Cador et al., 1985; Elliot and Nemeroff, 1986), and pretreatment with dopamine antagonist or destruction of dopamine in the nucleus accumbens with 6-hydroxydopamine abolishes this effect. Furthermore, the increase in motor activity
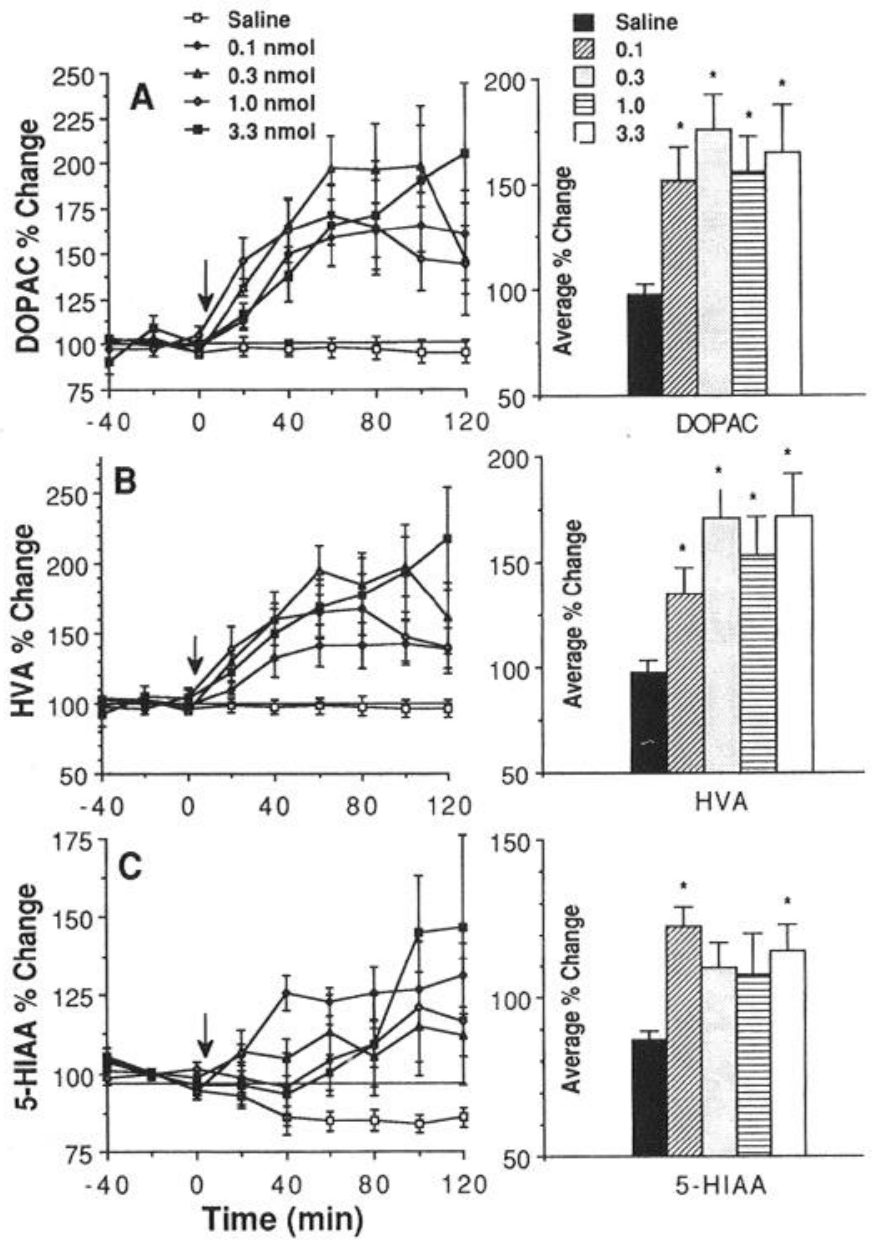

Figure 4. Effect of acute injection of neurotensin into the $\mathrm{A} 10$ region on extracellular levels of DOPAC, HVA, and 5-HIAA in the nucleus accumbens. The data were obtained simultaneously with the dopamine levels and behavior shown in Figure 3. $A$, DOPAC; $B, \mathrm{HVA}$; $C$, 5-HIAA. Symbols: $\square$, saline; $0.1 \mathrm{nmol} ; \triangle, 0.3 \mathrm{nmol} ; \diamond, 1.0 \mathrm{nmol} ; \mathbf{E}, 3.3$ nmol. See figure legend for Figure 3 for further details. ${ }^{*} p<0.05$, compared to saline injection using a 1-way ANOVA followed by a Dunnett's test (cumulative data). For the cumulative data, for DOPAC, $F(4,33)=6.492, p=0.001$; for HVA, $F(4,33)=7.623, p<0.001$; for 5 -HIAA, $F(4,33)=5.610, p=0.002$. For the time-course data, a leastsignificant difference test was used, and for DOPAC, $p<0.05$ difference from saline at $0.1,0.3$, and $1.0 \mathrm{nmol}$ from $40-120 \mathrm{~min}$, and at $3.3 \mathrm{nmol}$ from $60-120 \mathrm{~min}$; treatment $F(4,29)=6.492, p=0.001$; time $F(3,32)$ $=21.906, p<0.001$; interaction $F(32,232)=4.615, p<0.001$; for HVA, $p<0.05$ difference from saline at $0.3,1.0$, and $3.3 \mathrm{nmol}$ from $40-120 \mathrm{~min}$, and at $0.1 \mathrm{nmol}$ from $60-120 \mathrm{~min}$; treatment $F(4,29)=$ $7.624, p<0.001$; time $F(8,232)=21.136, p<0.001$; interaction $F(32$, $232)=5.032, p<0.001$; for 5-HIAA, $p<0.05$ difference from saline at $0.1 \mathrm{nmol}$ from $40-120 \mathrm{~min}$, at $0.3 \mathrm{nmol}$ at 60,100 , and $120 \mathrm{~min}$, at 1.0 and $3.3 \mathrm{nmol}$ from $100-120 \mathrm{~min}$; treatment $F(4,29)=5.610, p=$ 0.002 ; time $F(8,232)=4.414, p<0.001$; interaction $F(32,232)=$ $3.619, p<0.001$.

by neurotensin has been shown to be associated with an increase in the level of dopamine metabolites in a number of brain regions, including the nucleus accumbens (Kalivas et al., 1983a; Cador et al., 1989). Finally, neurotensin produces an increase in the firing frequency of A10 and A9 dopamine neurons (Innis et al., 1985; Pinnock, 1985; Shi and Bunney, 1988; Seutin et al., 1989).

Considering the numerous convergent data supporting activation of A10 dopamine neurons by neurotensin, it was sur- 

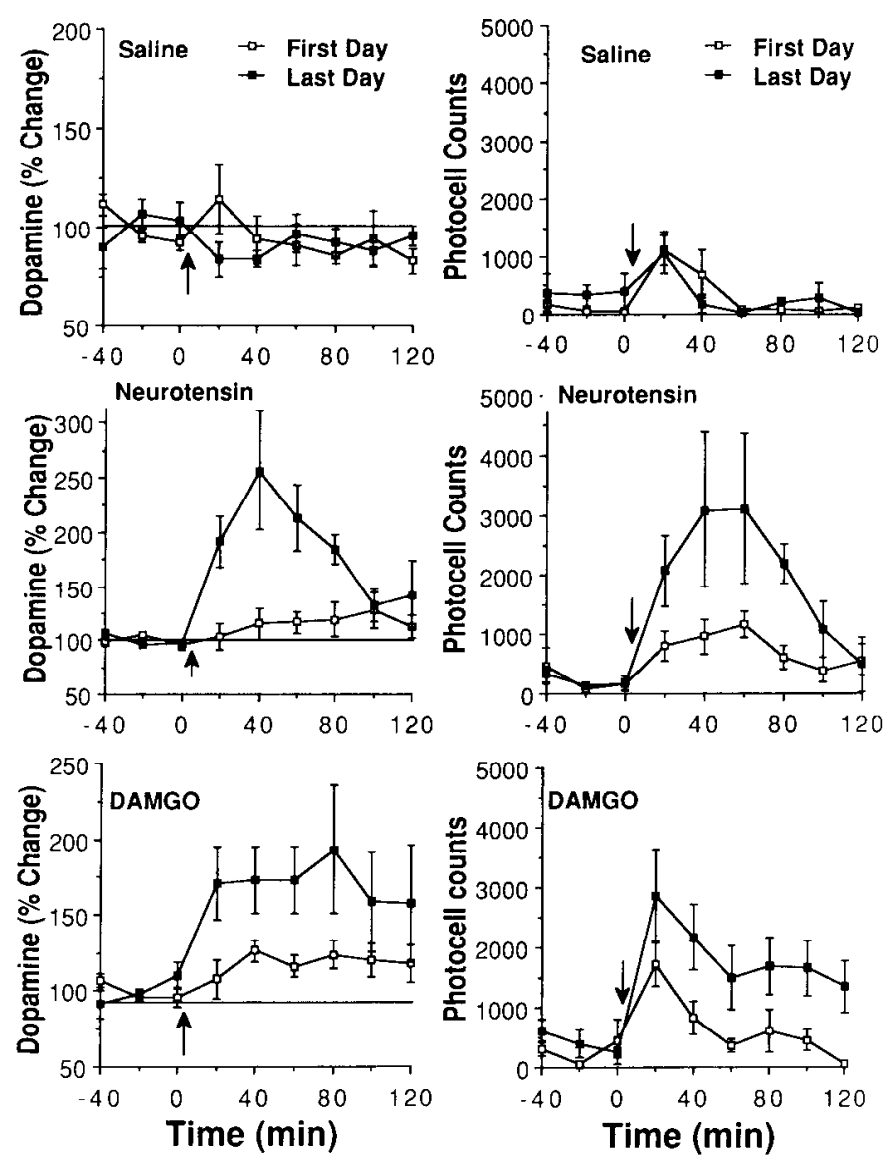

Figure 5. Effect of daily microinjection of neurotensin $(1.0 \mathrm{nmol})$ or DAMGO $(0.03 \mathrm{nmol})$ into the A 10 region on motor activity and extracellular dopamine levels in the nucleus accumbens. The dopamine data are shown as the mean \pm SEM percent change from the average of the 3 baseline measurements obtained prior to injection of peptide or saline. The baseline values are shown in Table I. The photocell data are shown as mean \pm SEM horizontal photocell counts. Rats received 4 daily injections of saline ( $A, N=5$ first day; $N=4$ last day), neurotensin ( $B, N=6$ both days) or DAMGO $(C, N=7$ both days) into the A10 region, followed 4-6 d later by a subsequent injection. The first and last injections were made in the photocell cage with a dialysis probe in the nucleus accumbens. The data were statistically analyzed using a 2-way repeated-measures ANOVA followed by a least-significant difference test for comparisons between the first and last day within a given time bin. For the dopamine data: for saline, treatment $F(1,7)=0.173, p=$ 0.690 ; time $F(8,56)=0.759, p=0.640$; interaction $F(8,56)=1.511$, $p=0.174 ; p<0.05$ for neurotensin at $28-80 \mathrm{~min}$, treatment $F(1,10)$ $=11.652, p=0.007$; time $F(8,80)-5.865, p<0.001$; interaction $F(8,80)=4.208, p<0.001$; for DAMGO, treatment $F(1,12)=5.101$, $p=0.043$; time $F(8,96)=4.66, p<0.001$; interaction $F(8,96)=$ $1.885, p=0.071$. For behavioral data, for saline, treatment $F(1,7)=$ $0.455, p=0.522$; time $F(8,56)=5.298, p<0.001$; interaction $F(8,56)=0.86, p=0.556$; for neurotensin, treatment $F(1,10)=4.973$, $p=0.050$; time $F(8,80)=5.754, p<0.001$; interaction $F(8,80)=$ $2.022, p=0.054 ; p<0.05$ for DAMGO at 40 and $120 \mathrm{~min}$, treatment $F(1,12)=12.350, p=0.004$; time $F(8,96)=7.063, p<0.001$; interaction $F(8,96)=1.28, p=0.263$.

prising that unlike DAMGO, the behavioral stimulant effect of neurotensin was not correlated with the elevation in extracellular dopamine in the nucleus accumbens. This indicates that the enhanced release of dopamine in the nucleus accumbens by neurotensin is not mediating the behavioral response. Postmortem neurochemical measurements of dopamine metabolites reveal that neurotensin injection into the $\mathrm{Al} 0$ region increases dopamine transmission in many limbic and cortical dopamine
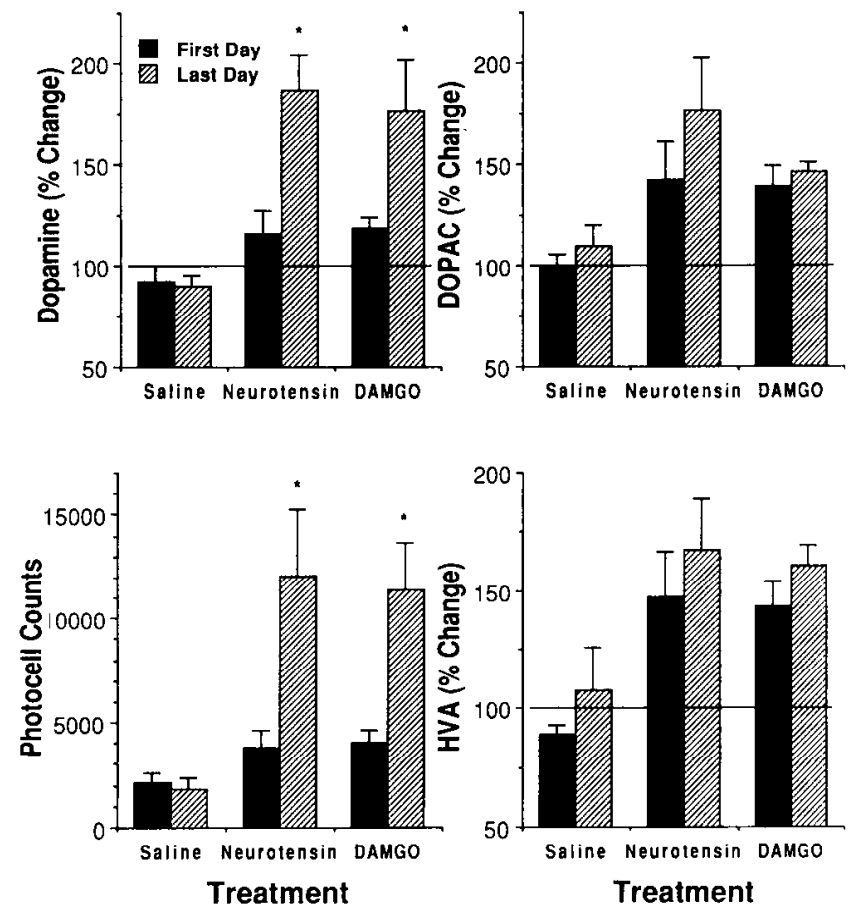

Figure 6. The cumulative data for the effect of daily neurotensin and DAMGO administration into the $\mathrm{A} 10$ region. ${ }^{*} p<0.05$ for comparison of first day of injection to the last day using a 1-way ANOVA. For the dopamine data, for saline $F(1,8)=0.540, p=0.824$; for neurotensin $F(1,11)=3.414, p=0.007$; for DAMGO $F(1,13)=2.681, p=0.020$. For the behavioral data, for saline $F(1,7)-0.540, p-0.824$; for neurotensin $F(1,11)=6.165, p<0.001$; for DAMGO $F(1,13)=9.781$, $p=0.009$. For the DOPAC data, for saline $F(1,7)=0.719, p=0.4251$; for neurotensin $F(1,11)=1.142, p=0.310$; for DAMGO $F(1,13)=$ $0.335, p=0.563$. For the HVA data, for saline $F(1,8)=1.232, p=$ 0.304 ; for neurotensin $F(1,11)=0.493, p=0.499$; for DAMGO $F(1,13)=1.463, p=0.252$.

terminal fields (Kalivas et al., 1983b; Cador et al., 1989), and perhaps extracellular dopamine levels in one of these nuclei would be better correlated with neurotensin-induced motor stimulation. Alternatively, dopamine may not be the sole determinant of neurotensin-induced behavior. Even the highest dose of neurotensin produced a maximal increase in extracellular dopamine of only $35 \%$, while the highest dose of DAMGO elicited a $110 \%$ increase. Thus, dopamine may be a more critical determinant of the motor response to DAMGO since it elicits a quantitatively greater increase in dopamine transmission. This is supported by the fact that daily neurotensin produced a greater increase in extracellular dopamine (up to a $150 \%$ increase), and under these conditions the behavioral response was significantly correlated with extracellular dopamine.

Previous studies have noted a difference between the behavioral effects of intra-A10 administration of neurotensin and opioids. While opioids produce a general increase in exploratory behaviors, neurotensin produces a preferential elevation in rearing behavior (Kelley et al., 1980; Kalivas et al., 1983b; Cador et al., 1985). Also, neurotensin produces a decrease, while opioids enhance feeding behavior (Cador et al., 1986), and neurotensin elicits a rate-decreasing effect, while opioids produce a rateincreasing cffcet in an operant task (Kclley et al., 1989). The differences between neurotensin and DAMGO observed in these studies and the present report may be a reflection of differences in the mechanisms by which these peptides activate dopamine 

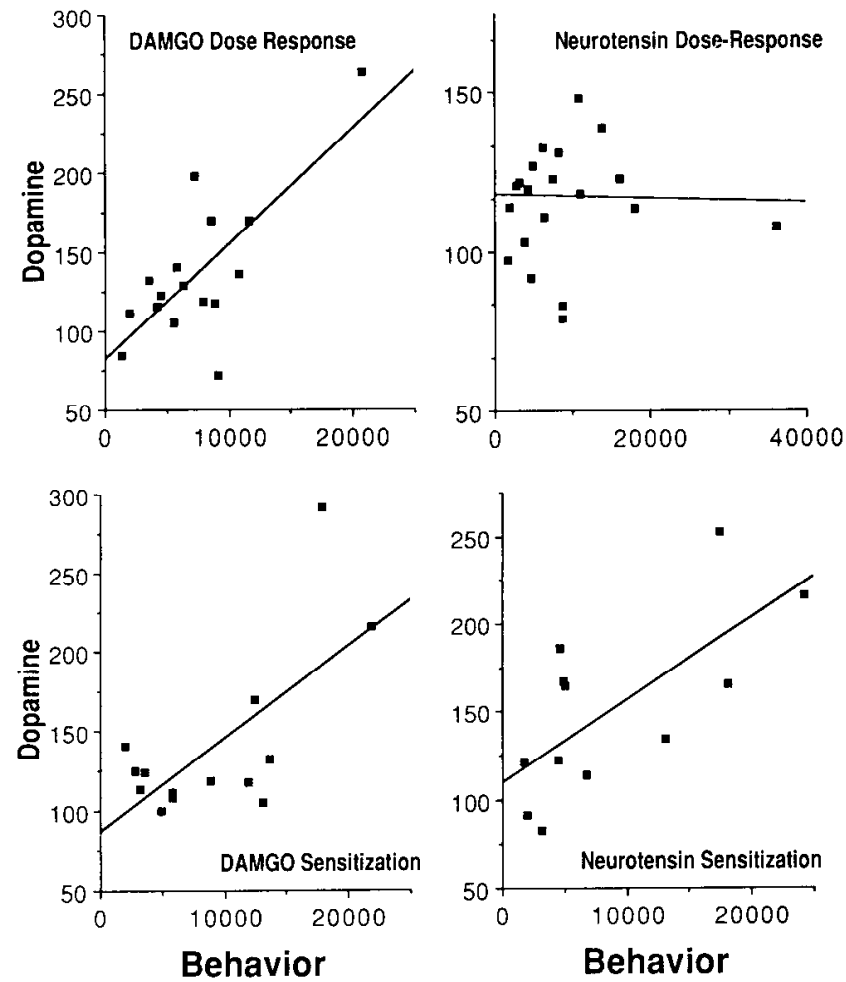

Figure 7. Plots of the correlation between behavior and extracellular levels of dopamine and its metabolites in the nucleus accumbens. These data were derived from Figures $1-6$. Behavior refers to the total horizontal photocell counts measured for $120 \mathrm{~min}$ after injection. The dopamine values were obtained by summing the percent changes in dopamine measured for 120 min after injection, then dividing by 6 (the number of dialysis samples collected over $120 \mathrm{~min}$ ) to yield the average percent change. The line was drawn by linear-regression analysis. See Table 2 for the correlation coefficients.

perikarya. Using light and electron microscopic receptor autoradiography, neurotensin receptors have been localized almost exclusively on dopamine neurons in the A10 region (Palacios and Kuhar, 1981; Quirion et al., 1985; Woulfe and Beaudet, 1989; Dana et al., 1989), while $\mu$-opioid receptors are on nondopaminergic neurons (Dilts and Kalivas, 1989). These anatomical data are consistent with the electrophysiological studies showing that neurotensin activates dopamine neurons both by direct stimulation and by disinhibition from dopamine $\mathrm{D}_{2}$ au- toreceptor activation (Pinnock et al., 1985; Shi and Bunney, 1988; Seutin et al., 1989), and that $\mu$-opioids act on nondopaminergic perikarya to disinhibit dopamine neuronal activity (Gysling and Wang, 1983; Matthews and German, 1984; Lacey et al., 1989). Based upon the fact that coadministration of the $\mathrm{GABA}_{\mathrm{A}}$ agonist, baclofen, with DAMGO into the $\mathrm{A} 10$ region abolishes DAMGO-induced motor activity, it has been postulated that activation of $\mu$-opioid receptors may inhibit GABA release in the $A 10$ region, thereby disinhibiting dopamine neuronal activity (Kalivas et al., 1990). In addition to these receptor-mediated effects, it was found that neurotensin binds with a relatively low affinity $(400 \mathrm{~nm})$ to the apamin binding site on a $\mathrm{Ca}^{+2}$-activated potassium channel to inhibit potassium flux (Hugues et al., 1982). It is possible that the concentrations of neurotensin achieved by microinjection could significantly inhibit this $\mathrm{K}^{+}$flux, which would activate dopamine neurons (Shepard and Bunney, 1988). Although many behavioral, neurochemical, and electrophysiological distinctions can be made regarding the actions of neurotensin and DAMGO in the A10 region, it is of interest that both neurotensin and opioids are self-administered into the A 10 region (Bozarth and Wise, 1980; Glimcher et al., 1987), indicating that both peptides have similar reinforcing effects.

In addition to dopamine, an elevation in extracellular dopamine metabolites in the nucleus accumbens was also produced by intra-A 10 administration of neurotensin or DAMGO. In general, the levels of DOPAC and IIVA were not significantly correlated with either photocell counts or the concentration of dopamine. The lack of correlation between dopamine and its metabolites indicates that the extracellular levels of DOPAC and HVA may not directly reflect dopamine release. Since DOPAC is derived partly from the intracellular metabolism of released dopamine that has been taken back into the dopamine terminal (Chang and Ramirez, 1989), in postmortem tissue it has often been used as an index of dopamine neurotransmission (Bannon and Roth, 1983; Kalivas et al., 1983a, b; Kato et al., 1984; Commissiong, 1985; Latimer et al., 1987). However, it has also been argued that extracellular DOPAC results primarily from the degradation of intracellular pools of newly synthesized dopamine, and not of recently released dopamine (Zetterstrom et al., 1988). With regard to the present study, it is possible that dopamine metabolites may directly reflect dopamine release, but that the increase in dopamine relcase in rcsponse to neurotensin or DAMGO may be occurring more extensively in a

Table 2. Correlations between locomotion and extracellular amines in the nucleus accumbens

\begin{tabular}{|c|c|c|c|c|}
\hline \multirow[b]{2}{*}{ Comparison } & \multicolumn{2}{|c|}{ Dose-response study } & \multicolumn{2}{|c|}{ Sensitization study } \\
\hline & $\begin{array}{l}\text { DAMGO } \\
(15)\end{array}$ & $\begin{array}{l}\text { Neurotensin } \\
(20)\end{array}$ & $\begin{array}{l}\text { DAMGO } \\
\text { (13) }\end{array}$ & $\begin{array}{l}\text { Neurotensin } \\
\text { (11) }\end{array}$ \\
\hline Locomotion vs dopamine & $0.735^{b}$ & 0.028 & $0.573^{a}$ & $0.661^{a}$ \\
\hline Locomotion vs DOPAC & 0.162 & 0.159 & 0.132 & 0.462 \\
\hline Locomotion vs HVA & 0.090 & 0.293 & 0.472 & 0.261 \\
\hline Locomotion vs 5-HIAA & 0.043 & 0.220 & - & - \\
\hline Dopamine vs DOPAC & 0.128 & 0.070 & 0.215 & $0.718^{a}$ \\
\hline Dopamine vs HVA & 0.034 & 0.191 & 0.170 & 0.527 \\
\hline DOPAC vs HVA & $0.868^{b}$ & $0.475^{a}$ & $0.665^{a}$ & $0.724^{a}$ \\
\hline
\end{tabular}

Data show the correlation coefficient $(r)$. The number in parentheses refers to the degrees of freedom in each group.

${ }^{a} p<0.05$, using regression analysis.

${ }^{b} p<0.005$. 

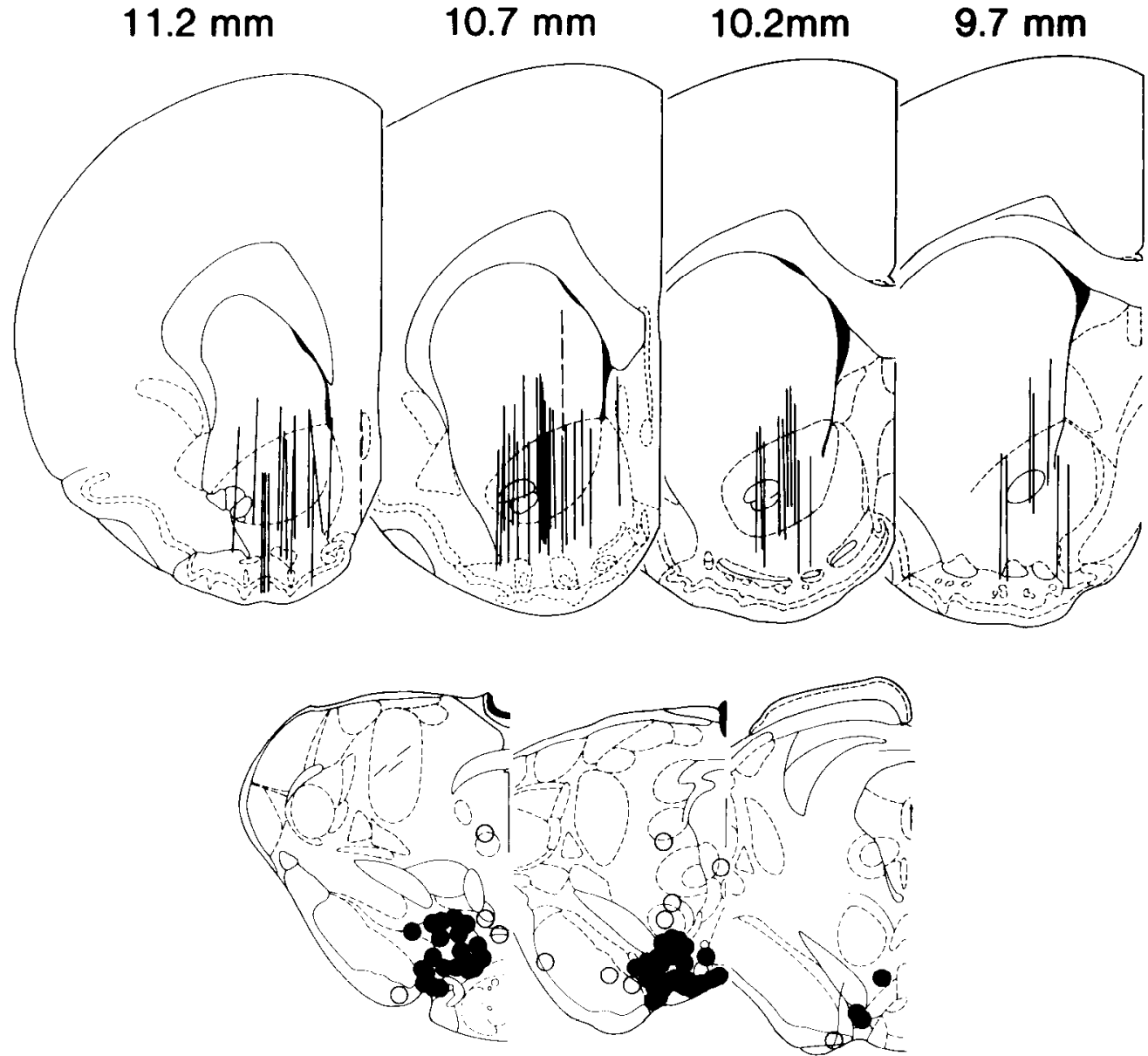

$4.2 \mathrm{~mm}$

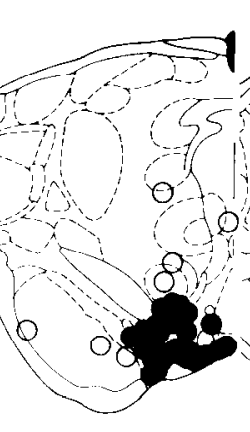

$3.7 \mathrm{~mm}$

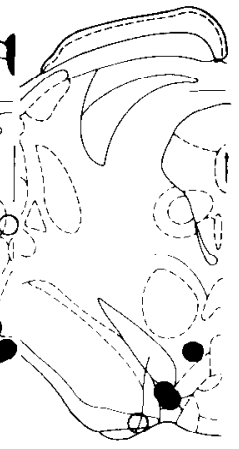

$3.2 \mathrm{~mm}$
Figure 8. Location of dialysis probes in the nucleus accumbens and injection cannula tips in the Al0 region of all rats used in this study. In the upper charting, the location of each probe is indicated by a vertical line corresponding to a $2 \mathrm{~mm}$ length of the exposed dialysis membrane. The dashed line indicates the 2 probes that did not have at least $50 \%$ of the dialysis membrane in the nucleus accumbens. In the lower charting, the filled circles indicate cannulae placement from data used in the study, while the open circles indicate cannulae placement determined to be outside the A10 dopamine region. Although the cannulae were bilaterally implanted, for illustrative purposes, the bilateral cannulae tips are both drawn on the same side when their relative location differed. Distances given refer to distance from the interaural line according to the atlas of Paxinos and Watson (1986). terminal field outside the nucleus accumbens. It would be expected that if not released in the immediate vicinity of the dialysis probe, dopamine would be rapidly metabolized and appear as DOPAC and HVA in the extracellular fluid adjacent to the probe (Rice et al., 1985).

The extracellular levels of the serotonin metabolite 5-HIAA were elevated by acute administration of both neurotensin and DAMGO. Although the increase in 5-HIAA following DAMGO was dose dependent, the increase after neurotensin was not over the dose range examined, with the lowest and highest doses of neurotensin producing statistically significant elevations. Previous studies have demonstrated an elevation (Garcia-Sevilla et al., 1978b), inhibition (Long et al., 1984), or no change (Widerlov et al., 1982) in postmortem serotonin synthesis or tissue concentrations of 5-HIAA after intracerebroventricular administration of neurotensin. In contrast, the majority of studies have found that activation of opioid receptors increases serotonin turnover in the brain (Yarbrough et al., 1973; Garcia-Sevilla et al., 1978a). Thus, the elevation in extracellular 5-HIAA is consistent with both peptides increasing serotonin transmission in the nucleus accumbens (however, see the discussion above regarding the physiological significance of monoamine metabolite measures). There are 3 possible explanations for the observed changes in 5-HIAA. (1) There are serotonin perikarya in the A10 region (Steinbusch, 1981), and activation of these neurons could enhance serotonin transmission in the nucleus accumbens. (2) The A10 region projects to the dorsal raphe (Domesick,
1988), and modulation of this projection could stimulate serotonin efferents to the nucleus accumbens. (3) There is behavioral and neurochemical evidence that serotonin transmission in the nucleus accumbens or striatum may regulate dopamine neurotransmission (Carter and Pycock, 1979; Kuzcenski and Segal, 1989). Thus, feedback onto serotonergic neurons in the dorsal raphe and/or terminals in the nucleus accumbens resulting from peptide-induced activation of the mesoaccumbens dopamine projection may elicit the elevation in extracellular 5-HIAA.

The augmentation in extracellular dopamine following daily administration of neurotensin or DAMGO into the $\mathrm{A} 10$ region is consistent with previous studies. Daily administration of $\mu$-opioids into the A 10 region has been shown to produce an augmented behavioral response upon subsequent administration (Joyce and Iversen, 1979; Vezina and Stewart, 1984; Kalivas et al., 1985). The augmented behavioral response was found to be associated with an augmented increase in the postmortem concentration of DOPAC and HVA in the nucleus accumbens (Kalivas, 1985). Likewise, the behavioral response to neurotensin has been shown to augment with daily administration and to be associated with an enhancement in the postmortem concentration of DOPAC in the nucleus accumbens (Elliot and Nemeroff, 1985; Kalivas and Taylor, 1985). While the present data indicate that enhanced dopamine release in the nucleus accumbens may mediate the behavioral augmentation produced by daily peptide injection into the A10 region, they do not indicate the site of cellular alteration allowing for the enhanced 
release of dopamine. Three possibilities exist: (1) a change in axon tcrminal regulation of dopamine release, (2) a change in somatodendritic regulation, making the neurons more easily stimulated, or (3) an alteration in the afferent regulation of the neuron promoting increased excitability. The present study does not distinguish between these mechanisms.

In summary, these data demonstrate acute microinjection of the $\mu$-agonist, DAMGO, and neurotensin into the $\mathrm{A} 10$ region elicits an increase in extracellular dopamine in the nucleus accumbens that is associated with the motor stimulant response. However, only after DAMGO was the increase in dopamine significantly correlated with behavior. The data also demonstrate that behavioral sensitization to either daily injection of neurotensin or DAMGO is associated with increased extracellular levels of dopamine in the nucleus accumbens, supporting the contention that behavioral sensitization to these peptides may be mediated by enhanced dopamine release in the nucleus accumbens.

\section{References}

Bannon MJ, Roth RH (1983) Pharmacology of mesocortical dopamine neurons. Pharmacol Rev 35:53-68.

Bozarth MA, Wise RA (1980) Intracranial self-administration of morphine into the ventral tegmental area. Life Sci 28:551-555.

Broekkamp CI.F, Phillips AG, Cools AT (1979) Stimulant effects of enkephalin injection into the dopaminergic A10 area. Nature 278: 560-562.

Cador M, Kelley AE, LeMoal M, Stinus L (1985) Behavioral analysis of the effect of neurotensin injected into the ventral mesencephalon on investigatory and spontaneous motor behavior in the rat. Psychopharmacology 85:37-46.

Cador M, Kelley AE, LeMoal M, Stinus L (1986) Ventral tegmental area infusion of substance $P$, neurotensin and enkephalin: differential effects on feeding behavior. Neuroscience 18:659-669.

Cador M, Rivet J-M, Kelley AE, LeMoal M, Stinus L (1989) Substance $P$, neurotensin and enkephalin injections into the ventral tegmental area: comparative study on dopamine turnover in several forebrain structures. Brain Res 486:357-363.

Carter C, Pycock C (1979) The effects of 5,7-dihydroxytryptamine lesions of extrapyramidal and mesolimbic sites on spontaneous motor behavior and amphetamine-induced stereotypy. Naunyn-Schmiedebergs Arch Pharmacol 312:235-238.

Chang GD, Ramirez VD (1989) Studies of the in vivo catabolism of exogenous dopamine as infused through a push-pull cannula implanted in the rat caudate nucleus. Brain Res 481:265-273.

Commissiong JW (1985) Monoamine metabolites: their relationship and lack of relationship to monoaminergic neuronal activity. Biochem Pharmacol 34:1127-1131.

Dana C, Vial M, Leonard K, Beauregard A, Kitabgi P, Vincent J-P, Rostene W, Beaudet A (1989) Electron microscopic localization of neurotensin binding sites in the midbrain tegmentum of the rat. I. Ventral tegmental area and interfascicular nucleus. J Neurosci 9:22472257.

Dilts RP, Kalivas PW (1989) Autoradiographic localization of muopioid and neurotensin receptors within the mesolimbic dopamine system. Brain Res 488:311-327.

Domesick VB (1988) Neuroanatomical organization of dopamine neurons in the ventral tegmental area. Ann NY Acad Sci 527:10-26.

Elliot PJ, Nemeroff CB (1986) Repeated neurotensin administration in the ventral tegmental area: effects on baseline and d-amphetamineinduced locomotor activity. Neurosci Lett 68:239-244.

Garcia-Sevilla JA, Ahtee L, Magnasson J, Carlson A (1978a) Opiatereceptor mediated changes in monoamine synthesis in rat brain. $\mathbf{J}$ Pharm Pharmacol 30:613-621.

Garcia-Sevilla JA, Magnusson J, Carlsson A, Leban J, Folkers K (1978b) Neurotensin and its amide analogue [Gln $\left.{ }^{4}\right]$-neurotensin: effects on brain monoamine turnover. Naunyn-Schmiedebergs Arch Pharmacol 305:213-218.

Glimcher PW, Giovino AA, Hoebel BG (1987) Neurotensin self-injection in the ventral tegmental area. Brain Res 403:147-150.
Gysling K, Wang RY (1983) Morphine-induced activation of A10 dopamine neurons in the rat brain. Brain Res 277:119-127.

Hugues M, Romey G, Duval D, Vincent JP, Lazdunski M (1982) Apamin as a selective blocker of the calcium-dependent potassium channel in neuroblastoma cells: voltage-clamp and biochemical characterization of the toxin receptor. Proc Natl Acad Sci USA 79:13081312 .

Innis RB, Andrade R, Aghajanian GK (1985) Substance K excites dopaminergic and nondopaminergic neurons in rat substantia nigra. Brain Res 335:381-383.

Joyce EM, Iversen SD (1979) The effect of morphine applied locally to mesencephalic dopamine cell bodies on spontaneous motor activity in the rat. Neurosci Lett 14:207-212.

Joyce EM, Koob GF, Strecker R, Iversen SD, Bloom FE (1981) The behavioral effects of enkephalin analogues injected into the ventral tegmental area and globus pallidus. Brain Res 221:359-370.

Kalivas PW (1985) Sensitization to repeated enkephalin administration into the ventral tegmental area of the rat. II. Involvement of the mesolimbic dopamine system. J Pharmacol Exp Ther 235:544-550.

Kalivas PW, Duffy P (1990) The effect of acute and daily cocaine treatment on extracellular dopamine in the nucleus accumbens. Synapse 5:48-58.

Kalivas PW, Taylor S (1985) Effect of daily neurotensin injection into the ventral tegmental area. Brain Res 358:70-76.

Kalivas PW, Burgess SK, Nemeroff CB, Prange AJ Jr (1983a) Behavioral and neurochemical effects of neurotensin microinjection in to the ventral tegmental area of the rat. Neuroscience 8:495-505.

Kalivas PW, Widerlov E, Stanley D, Breese GR, Prange AJ Jr (1983b) Enkephalin action on the mesolimbic dopamine system: a dopaminedependent and a dopamine-independent increase in locomotor activity. J Pharmacol Exp Ther 227:229-237.

Kalivas PW, Duffy P, Eberhardt H (1990) Modulation of A10 dopamine neurons by $\mathrm{G} \wedge \mathrm{B} \Lambda$ agonists. J Pharmacol Exp Ther 253:858866.

Kato T, Ishii K, Ikeda M (1984) Voltammetry in unanesthetized rat: increases of striatal dopamine turnover after unilateral haloperidol injection into the substantia nigra. Neurosci Lett 50:263-267.

Kazahaya Y, Akimoto K, Otsuki S (1989) Subchronic methamphetamine treatment enhances methamphetamine- or cocaine-induced dopamine efflux in vivo. Biol Psychiatry 25:903-912.

Kelley AE, Stinus L, Iversen SD (1980) Interaction between D-AlaMet-enkephalin, A10 dopamine neurons, and spontaneous behavior in the rat. Behav Brain Res 1:3-24.

Kelley AE, Cador M, Stinus I, LeMoal M (1989) Neurotensin, substance $P$, neurokinin-a, and enkephalin: injection into ventral tegmental area in the rat produces differential effects on operant responding. Psychopharmacology 97:243-252.

Kuzcenski R, Segal DS (1988) Psychomotor stimulant-induced sensitization: behavioral and neurochemical correlates. In: Sensitization in the nervous system (Kalivas PW, Barnes CD, eds), pp 175-206. Caldwell, NJ: Telford.

Kuzcenski R, Segal DS (1989) Concomitant characterization of behavioral and striatal neurotransmitter response to amphetamine using in vivo microdialysis. J Neurosci 9:2051-2062.

Lacey MG, Mercuri NB, North RA (1989) Two cell types in rat substantia nigra zona compacta distinguished by membrane properties and the actions of dopamine and opioids. J Neurosci 9:1233-1241.

I atimer I. G, Duffy P, Kalivas PW (1987) Mu opioid receptor involvement in enkephalin activation of dopamine neurons in the ventral tegmental area. J Pharmacol Exp Ther 241:328-337.

Long JB, Kalivas PW, Youngblood WW, Prange AJ Jr, Kizer JS (1984) Possible involvement of serotonergic neurotransmission in neurotensin but not morphine analgesia. Brain Res 310:35-41.

Matthews RT, German DC (1984) Electrophysiological evidence for excitation of rat ventral tegmental area dopamine neurons by morphine. Neuroscience 11:617-625.

Milliken GA, Johnson DE (1984) Analysis of messy data. Vol 1: designed experiments, pp 326-337. Belmont, CA: Lifetime Learning.

Palacios JM, Kuhar MJ (1981) Neurotensin receptors are located on dopamine-containing neurons in rat midbrain. Nature 294:587-589.

Paxinos G, Watson C (1986) The rat brain in stereotaxic coordinates, 2nd ed. New York: Academic.

Pelligrino LK, Pelligrino AS, Cushman AJ (1979) A stereotaxic atlas of the rat brain. New York: Plenum.

Phillips $\Lambda G$, Blaha CD, Fibiger HC, Lane RF (1988) Interactions 
between mesolimbic dopamine neurons, cholecystokinin and neurotensin: evidence using in vivo voltammetry. Ann NY Acad Sci 537: $347-361$.

Pinnock RD (1985) Neurotensin depolarizes substantia nigra dopamine neurones. Brain Res 338:151-154.

Post RM, Weiss SRB (1988) Sensitization and kindling: implications for the evolution of psychiatric symptomatology. In: Sensitization in the nervous system (Kalivas PW, Barnes CD, eds), pp 257-293. Caldwell, NJ: Telford.

Quirion RC, Chiueh CC, Fverist HD, Pert A (1985) Comparative localization of neurotensin receptors on nigrostriatal and mesolimbic dopaminergic terminals. Brain Res 327:385-389.

Rice ME, Gerhardt GA, Hierl PM, Nagy G, Adams RN (1985) Diffusion coefficients of neurotransmitters and their metabolites in brain extracellular fluid space. Neuroscience 15:891-902.

Robinson TE, Becker JB (1986) Enduring changes in brain and behavior produced by chronic amphetamine administration: a review and evaluation of animal models of amphetamine psychosis. Brain Res Rev 11:157-198.

Robinson TE, Whishaw IQ (1988) Normalization of extracellular dopamine in striatum following recovery from a partial unilateral 6-OHDA lesion of the substantia nigra: a microdialysis study in freely moving rats. Brain Res 450:209-224.

Robinson TE, Jurson PA, Bennett JA, Bentgen KM (1988) Persistent sensitization of dopamine neurotransmission in ventral striatum (nucleus accumbens) produced by prior experience with (+)-amphetamine: a microdialysis study in freely moving rats. Brain Res 462 : $211-222$

Seutin V, Mossotte L, Dresse A (1989) Electrophysiological effects of neurotensin on dopaminergic neurones of the ventral tegmental area of the rat in vitro. Neuropharmacology 28:949-954.

Shepard PD, Bunney BS (1988) Effects of apamin on the discharge properties of putative dopamine-containing neurons in vitro. Brain Res 463:380-384.

Shi W-X, Bunney BS (1988) 8-Bromo-cAMP mimics the effects of neurotensin in midbrain dopamine neurons: a study in brain slice. Soc Neurosci Abstr 14:35.4.

Steinbusch HWM (1981) Distribution of serotonin-immunoreactivity in the central nervous system of the rat. Cell bodies and terminals. Neuroscience 6:557-618.

Vezina P, Stewart J (1984) Conditioning and place-specific sensitization of increases in activity induced by morphine in the VTA. Pharmacol Biochem Behav 20:925-934.

Widerlov E, Kilts CD, Mailman RB, NemeroffCB, McCown TJ, Prange AJ Jr, Breese GR (1982) Increase in dopamine metabolites in rat brain by neurotensin. J Pharmacol Exp Ther 222:1-6.

Woulfe J, Beaudet A (1989) Immunocytochemical evidence for direct connections between neurotensin-containing axons and dopaminergic neurons in the rat ventral midbrain tegmentum. Brain Res 479:402406.

Yarbrough GG, Buxbaum DM, Sanders-Bush E (1973) Biogenic amines and narcotic effects. II. Serotonin turnover in the rat after acute and chronic morphine administration. J Pharmacol Exp Ther 185:328335.

Zetterstrom T, Sharp T, Collin AK, Ungerstedt U (1988) In vivo measurement of extracellular dopamine and DOPAC in rat striatum after various dopamine releasing drugs; implication for the origin of extracellular DOPAC. Eur J Pharmacol 148:327-334. 